\title{
Sağlık Yöneticilerinin E-Nabız Uygulamalarının Kullanımına Yönelik Tutumlarının Doğrulayıcı Faktör Analizi İle Belirlenmesi
}

\author{
Determining The Attitude Of Health Managers Towards The Use Of E-Pulse Applications With Confirmatory \\ Factor Analysis
}

Fuat YALMAN ${ }^{1}$

\begin{abstract}
ÖZ
$\mathrm{Bu}$ çalışmanın temel amacı; e-nabız uygulamalarının kullanımına yönelik tutumların doğrulayıcı faktör analizi ile belirlenmesidir. Araştırmanın çalışma evrenini Türkiye'de faaliyet gösteren JCI (Joint Commission International) akreditasyon belgeli 48 adet özel hastane oluşturmaktadır. Özel hastanelerin konuyla ilgili orta ve/veya üst kademe yöneticileri ise, araştırma birimini oluşturmuştur. Örneklem grubu ise 1215 katılımcıdan oluşmaktadır. Veriler online (internet üzerinden) anket tekniği ile toplanmıştır. Araştırmada kolayda örnekleme yöntemi tercih edilmiştir. Analiz programları olarak SPSS ve AMOS paket programları kullanılmıştır. Araştırmada açıklayıcı faktör analizi ve doğrulayıcı faktör analizi teknikleri kullanılarak faktörler belirlenmiştir. Açıklayıcı ve doğrulayıcı faktör analizleri ile elde edilen bulgular, modelin geçerliliğinin sağlandığını göstermiştir. Açıklayıcı faktör analizi ile ortaya konulan yap1 geçerliliği, doğrulayıcı faktör analizi ile doğrulanmıştır. Güvenilirlik katsayısı Alfa=0,968 olarak bulunmuştur. $\mathrm{Bu}$ değer $0,80 \leq \alpha<1,00$ arasında olduğundan, ölçek yüksek derecede güvenilirdir. Bunun yanı sıra yöneticilerin e-nabız uygulamasına yönelik tutumlarının eğitim düzeyi, yaş durumu ve cinsiyetlerine göre anlamlı farklılıklar gösterdiği tespit edilmiştir. Dolayısıyla "e-nabız ölçeği” için geçerlilik ve güvenilirlik sağlandığından "e-nabız ölçeği”" enabız uygulamalarının kullanımına yönelik tutumları ve beklentileri ölçmek için rehber ölçek olarak kullanılabilir. Aynı zamanda e-nabız uygulamasına yönelik olarak, çoğunlukla eğitim düzeyi yüksek, orta yaş gurubunda olan ve kadın yöneticilerin diğerlerine göre daha olumlu tutum içerisinde oldukları sonucuna varılmıştır. Sonuç olarak bu çalışma, sağlık yöneticilerinin e-nabız konusunda neleri, ne kadar ve ne derece doğru bildiklerinin ve e-nabız uygulamalarını ne siklıkla kullandıklarının tespit edilmesinde düzenli ve sürdürülebilir e-sağlık hizmetlerinin kullanılmasında ölçülü bir katkı sağlamaktadır.
\end{abstract}

Anahtar Kelimeler: E-nabız uygulamaları, Sağlık yöneticileri, Doğrulayıcı faktör analizi.

\begin{abstract}
The main purpose of this study is to determine the attitudes towards the use of e-pulse applications by confirmatory factor analysis. The universe of the research constitutes 48 private hospitals operating in Turkey and having JCI accreditation certificate. The middle and upper level managers of private hospitals are accepted as research units. The sample group consists of 1215 participants. The data were collected by online survey technique. In the study, convenience sampling method was preferred. SPSS and AMOS package programs were used in the analysis of the data. Factors were determined using explanatory factor analysis and confirmatory factor analysis techniques in the study. Findings obtained with explanatory and confirmatory factor analyzes showed that the validity of the model was ensured. The construct validity revealed by the explanatory factor analysis was also confirmed by the confirmatory factor analysis. The reliability coefficient alpha was found as 0.968. Since this value is between $0.80 \leq \alpha<1.00$, the scale is highly reliable. In addition, it was determined that managers' attitudes towards epulse application show significant differences according to thehir education level, age and gender. Therefore, since validity and reliability are provided for "e-pulse scale", "e-pulse scale" can be used as a guiding scale to measure attitudes and expectations towards the use of e-pulse applications. At the same time, it was concluded that mostly high education level, middle age group and female managers have more positive attitudes towards e-pulse application than others. As a result, this study makes a measured contribution to the determination of what, how much and to what extent health managers know e-pulse correctly and how often they use e-pulse applications and to use regular and sustainable e-health services.
\end{abstract}

Keywords: E-pulse applications, Health managers, Confirmatory factor analysis.

\footnotetext{
*Bu araştırma, Düzce Üniversitesi Bilimsel Araştırma ve Yayın Etik Kurulu’ndan etik kurul onay izni alınarak gerçekleştirilmiştir (Tarih: 03.12.2020, karar no: 2020/247).

${ }^{1}$ Dr. Öğr. Üyesi, Düzce Üniversitesi İşletme Fakültesi Sağlık Yönetimi Bölümü, fuatyalman@duzce.edu.tr, ORCID: 0000-0002-1041-1837

İletișim / Corresponding Author: $\quad$ Fuat YALMAN 28.12.2020

e-posta/e-mail:

fuatyalman@duzce.edu.tr

Kabul Tarihi/Accepted: $\quad 16.12 .2021$
} 


\section{GIIRIŞ}

Sağl1k, hem gelişmiş hem de gelişmekte olan ekonomilerde en hızlı büyüyen sektörler arasındadır. E-sağlık ise, paydaşlarını bilgi arama ve iletişim süreçleriyle desteklemek için interneti ve tüm yeteneklerini kullanarak bu sektördeki patlayıcı büyümeye daha da katkı sağlamaktadır. ${ }^{1}$ E-sağlık kavramı, 21. yüzyılın ilk yıllarında ortaya çıkmıştır. Esağlık, sağlik sektöründe elektronik bilgi ve iletişim teknolojisinin hem yerel sahada hem de geniş coğrafi bölgelerde klinik ve eğitim araştırmaları ve idari amaçlarla birlikte kullanılması faaliyetidir. E-sağlık hizmetlerinin kullanımı; yerel, bölgesel ve ulusal düzeylerde ağ oluşturmayı geliştirmiş, küresel düşünceyi kolaylaştırmış ve sağlık hizmetlerini iyileştirmiştir. ${ }^{2}$ E-sağlık, tüketicilerin sağlik hizmetlerine erişimini kolaylaştırmak ve sağlık hizmet kalitesini iyileştirmekle ilgilidir. Aynı zamanda esağlık, doktorlar, hemşireler, hasta bakıcılar ve hastalar için yeterli bilgi sağlamayı kapsamaktadır. Bunun yanı sıra, hasta dostu hizmetler oluşturmak için operasyonel verimliliği artırmakla da ilgilidir. ${ }^{1}$

Aynı zamanda sağlık hizmetleri, bilgi yoğun bir sektördür ve sağlık profesyonelleri, bir kişinin bakımı hakkında günlük kararlarını bildirmek için ihtiyaç duydukları zaman ve yerde doğru ve kapsamlı bilgilere erişime güvenirler. Ancak el yazısı kâğıt kayıtlarının, sağlık bilgilerini oluşturma, yakalama ve paylașma șekilleri konusunda, bilgi ve iletişim teknolojilerinden büyük ölçüde yoksun olduğu dile getirilmiştir. Aynı zamanda el yazısı kâğıt kayıtları tutmanın, parayı ve kıt kaynakları israf ettiği, hasta güvenliğini tehlikeye attığı ve bakım kalitesini düşürdüğü öngörülmektedir. ${ }^{3}$ Bundan dolayı mobil teknolojideki gelişmeler, sağlık hizmeti sunum seçeneklerinin kapsamını genişletmek için artan çözümler olarak görülmektedir. Çünkü elektronik sağlık sistemleri sayesinde sağllk bilgilerine esnek erişim sağlanmaktadır. ${ }^{4}$

Mobil uygulamalar, genellikle bir cep telefonuna veya tablete indirildikten sonra kullanılabilen yazılım programlarıdır. ${ }^{5}$ Mobil uygulamalar, diğer birçok alanda olduğu gibi sağlık hizmetleri alanında da giderek yaygın hale gelmiștir. ${ }^{6}$ Türkiye'deki insanların yarısından fazlasının (yaklaşık \% 65'inin) sağlık bilgisi almak için internet ve mobil uygulamaları kullandığı belirtilmiştir. ${ }^{7}$ Diğer taraftan kişisel sağlık sistemleri, hastaların kendi durumlarını takip etmelerini ve bilinçli kararlar vermelerini kolaylaştıran ve sürekli gelişen bir alan olarak görülmektedir. Çünkü kişisel sağlık kayıt sisteminin temel amacı, hastaya, bir bireyin sağlık ve elektronik olarak depolanan sağlık hizmetleri hakkındaki kişisel sağlık kayıtlarını sistematik olarak toplama, koruma ve yönetme yeteneği sunmaktadır. ${ }^{8}$

Son y1llarda mobil uygulamaların her geçen gün daha da önem kazandığı ve işletmeleri, sosyal yaşamı ve yaşam tarzını etkilediği görülmektedir. Çünkü sağlık uygulamalarının hızla artan kullanımının, yalnızca vatandaşların yaşam kalitesini iyileştirmeye değil, aynı zamanda sağlık hizmetlerini de iyileștirmeye yardımc1 olduğu görülmüsştür. Aynı zamanda glikoz okuma ve tıbbi görüntü alma ve tıbbi bilgileri görüntüleme gibi özellikleri ile sağlık bilgilerini yönetmek ve gözlemlemek için hekimler ve hastalar tarafindan kullanılan mobil sağlık uygulamaları, mobil cihazları tıbbi cihazlara dönüştürür. ${ }^{9} \mathrm{Bu}$ bağlamda, mobil sağlık uygulamalarının potansiyel avantajları; hızlı teşhis koyulabilmesi, sağlık durumunu izlemek için geri bildirim sağlaması, sağlıklı davranışları teşvik etmesi, tedavi ve rehabilitasyona kolay erişim sağlaması, elektronik reçete vermesi, onaya daha hızlı erișim sağlaması ve bekleme sürelerini kısaltması olarak belirtilmiştir. ${ }^{10}$

Aynı zamanda mobil sağl1k, sağlık sistemlerinin işlevlerini (raporlama prosedürü gibi) iyileştirmek için mobil telefon ağları gibi elektronik cihazların kullanımı yoluyla hali hazırda mevcut sağlık sistemlerinin verimliliğini ve doğruluğunu genişletir. Mobil sağlık, mobil telekomünikasyon ve multimedya teknolojilerinin kullanımını ve bunların mobil sağlık hizmeti sunum sistemleriyle entegrasyonunu içeren kablosuz tele tıp yoluyla gerçekleşir. Bununla birlikte 
mobil sağlık; erişim, kalite, satın alınabilirlik, kaynakların eşleştirilmesi ve davranış normları gibi sağlı hizmeti zorluklarını mobil teknolojiler aracılığıyla ele almak için kullanılmaktadır. Mobil sağlık uygulamaları, insanları ve ürünleri içeren bir ağdır ve dijital teknolojileri kullanarak onları birbirine bağlayan mekanizmalardır. ${ }^{3}$

Bununla birlikte mobil uygulamalardaki son gelişmelerden dolayı organizasyonlar, pazarlama yeteneklerini geliştirmek için büyük ölçüde mobil teknolojilerin kullanımına odaklanmak zorunda kalmışlardır. Son araştırmalar temel olarak mobil uygulamaların benimsenmesine yöneliktir. ${ }^{11}$ Mobil uygulamalardaki deneyimlerinden memnun olan kişiler, bu tür uygulamaları kullanmaya devam etme konusunda daha motive olurlar ve bu da bir mobil uygulama kültürü oluşmasına zemin hazirlar. $^{12}$

Kişisel sağlık bilgilerinin yönetilebildiği ve T.C. Sağlık Bakanlığı tarafından desteklenen akıllı mobil sağlık uygulamalarının en önemlilerinden birisi de e-nabız uygulamalarıdır. E-nabız sistemi, tüm bireylerin laboratuvar bulguları, tan1tedavi sonuçları, hastane kayıtları ve randevu geçmişleri dahil tüm sağlı verilerine ulaşabilmelerini ve bu verileri kendi tercihleri doğrultusunda kullanabilmelerini ve aynı zamanda bunlardan istedikleri zaman faydalanabilmelerini sağlayan bir uygulamadır. E-nabız uygulaması sayesinde tüm sağlık kurum ve kuruluşlarında yapılan muayene, tetkik-tahlil ve ameliyatlar tek bir veri tabanında toplanabilmekte ve toplanan bu sağlık kayıtlarına; tüm kullanıcılar, ilgili sağlık personelleri ve sağlık kuruluşları, yetkileri doğrultusunda ulaşabilmektedir. ${ }^{13}$

E-nabız, vatandaşların ve sağlık çalışanlarının sağlık kurumlarından toplanan sağlık verilerine internet ve mobil cihazlar aracılığıyla ulaştıkları bir uygulamadır. Aynı zamanda muayene ve tedaviler nerede yapılırsa yapılsın, tüm sağlık bilgilerinin yönetilebileceği, tıbbi geçmişlere tek bir yerden erişilebileceği kişisel sağlık kayıt sistemidir. İnternet üzerinden güvenle erişilebilen dünyanın en büyük ve en kapsamlı sağlık bilgi altyapısı olup, sağlık kayitlarının hastalar tarafindan zaman ve kapsam sınırlaması ile yetkilendirilmiş hekimler tarafından değerlendirilmesini sağlayarak teșhis ve tedavinin kalitesini ve hızını arttırmaktadır ve aynı zamanda hasta ve doktor arasında güçlü bir iletişim ağı oluşturmaktadır. Öte yandan e-devlet yaklaşımları kapsamında T.C. Sağlık Bakanlığ 1 tarafından geliştirilen ve mobil sağlık uygulaması olan e-nabız mobil uygulaması; veri paylaşımının ve iletim süreçlerinin gizliliğine dikkat etmektedir. ${ }^{14}$

Günümüzde hastaların, mobil uygulama kullanımı için hasta seçeneklerini veya sağlık izleme uygulamalarını indirmek ve çalıştırmak için mobil cihazlarını kullanma ilgisine dair çok az bilginin var olduğu dikkati çekmiştir. Aynı zamanda bu alanda sağlık uygulamalarının ne kadar başarılı ve işlevsel olduğu bilinmemektedir. Diğer taraftan Türkiye'de mobil uygulamaları kullanma kültürünün artmış olmasına rağmen, bireyler tarafindan nasıl kullanıldığ ve günlük yaşamları için ne kadar yararlı olduğu da tam anlamiyla bilinmemektedir. $\mathrm{Bu}$ çalıșmanın amacı, e-nabız uygulamalarının kullanımına yönelik tutumlar1 belirlemek ve e-nabiz uygulamalarının tercihini etkileyen faktörleri yapısal eşitlik analizi ile tespit etmektir. Bunun yanı sıra bu araştırma ile nüfusun her gün arttığı gelişmekte olan ülkelerde sağlık hizmetleri sisteminin yararlarına ve zorluklarına katkıda bulunmak hedeflenmiştir. 


\section{MATERYAL VE METOT}

\section{Araştırmanın Yöntemi}

Araştırmada, araştırmanın problemi, veri toplama aracı ve yapılacak analizler göz önünde bulundurularak nicel araştırma yöntemi kullanılmıştır.

\section{Araştırmanın Etik Yönü}

Bu araştırma, Düzce Üniversitesi Bilimsel Araştırma ve Yayın Etik Kurulu'ndan etik kurul onay izni alınarak gerçekleştirilmiştir (Tarih: 03.12.2020, karar no: 2020/247). Tüm katılımcılardan sözlü onam alındı.

\section{Araştırmanın Kavramsal Modeli}

E-nabız uygulamasının kullanılmasında etkili olan faktörler ile bu faktörler arasındaki yapısal ilişkilerin tespit edilmesi kapsamında araştırmanın kavramsal modeli tasarlanmıştır. Araştırmanın kavramsal modeli, araştırmanın temel değişkenleri (enabız uygulamasının kullanılmasında etkili olan faktörler) arasındaki yapısal ilişkileri tartışmaktadır.

\section{Araştırma Birimi, Evren ve Örneklemi}

Araştırmanın evrenini Türkiye'de faaliyet gösteren JCI (Joint Commission International) akreditasyon belgeli 48 adet özel hastane oluşturmaktadır. Özel hastanelerin konuyla ilgili orta ve/veya üst kademe yöneticileri araştırma birimini, 1215 katılımc1 ise örneklemini olușturmuştur. Veriler online (internet üzerinden) anket tekniği ile toplanmıştır. Araştırmada kolayda örnekleme yöntemi kullanılmıştır.

\section{Veri Toplama Yöntemi}

Araştırma verilerini toplamak için internet üzerinden anket tekniği (online anket) kullanılmıştır. Çalışma, Türkiye'de faaliyet gösteren JCI (Joint Commission International) akreditasyon belgeli özel hastanelerin orta ve/veya üst kademe yöneticilerinin kesitsel bir araştırması olarak gerçekleştirilmiştir. Anket formu, iki bölümden oluşmaktadır. Birinci bölümde, 23 önermeden oluşan e-nabız uygulamasının kullanılmasında etkili olan faktörleri belirlemeye yönelik ifadeler yer alırken; ikinci bölümde ise yöneticilerin temel özelliklerine yönelik ifadeler yer almaktadır.

\section{Araştırmada Kullanılan Ölçekler}

Katılımciların e-nabiz uygulamasinın kullanımına yönelik tutumlarını etkileyen faktörleri belirlemek için kullanılan ölçek formu, gerekli literatür taraması sonucunda araştırmacı tarafından bizzat oluşturulmuştur ve uyarlanmıştır.

\section{Veri Analizi Yöntemi}

Araştırma kapsamında toplanan veriler SPSS ve AMOS istatistiksel analiz programlarına yüklenmiş ve analiz edilmiştir. Verilere öncelikle güvenilirlik analizi yapılmış, daha sonra araştırmanın demografik özellikleri varyans, ortalama, frekans dağılımı ve oransal açıdan incelenmiştir. Ayrıca gizil değişkenlerin, gözlenen değişkenler açısından nasıl açıklanabildiklerini ortaya koymak için, AMOS paket programı ile doğrulayıcı faktör analizi uygulanmıştır.

\section{Veri Seti Analiz Kriterleri}

Verilerin analizinde, betimsel istatistikler, keşifsel faktör analizi ve doğrulayıcı faktör analizi teknikleri kullanılmıştır.

\section{Açıklayıcı (Keşifsel) Faktör Analizi (AFA) için Kriterler}

Maddelerin faktör yük değerini ortaya koymak için ortak faktör varyansı ve temel bileşenler analizi teknikleri kullanılmıştır. Faktör yük değerleri için alt sınır 0.45 olarak belirlenmiștir. Varimax dik döndürme yöntemi uygulanmıştır. Birden fazla faktör altında toplanan ve faktör yük değerleri arasındaki farkın 0.10 'dan daha düşük olduğu sorular anket formundan çıkarılırken, özgün değeri 1'in üstünde olan faktörler analize tabi tutulmuştur. Açıklanan varyans oranı olarak \%55 sınır değer kabul edilmiș ve faktörlerin bağımsızlı̆̆ını, yorumlamada açıklık ve anlamlılığını sağlamak amacıyla faktörlere sonrasında rotasyon yapılmıștır. Rotasyon tekniği olarak da dik döndürme tekniği uygulanmıştır. 
Doğrulayıcı Faktör Analizi (DFA) için Kriterler

Her bir yap1 üzerindeki gözlenen değişkenlerin standartlaştırılmış yüklemelerinin, anlamlı ve üstün yakınsak geçerliliğin 0.5 'den yüksek olup olmadığı kontrol edilmiştir. Daha sonra geçerliliği kontrol etmek için bileşik güvenilirlik (CR) testi yapılmıştır. Her bir yapı için çıkarılan ortalama varyansın, diğer yapılarla paylaşılan varyansından daha büyük olması durumunda ayırt edici geçerliliğin sağlandığı durumu kontrol edilmiştir.

\section{BULGULAR VE TARTIŞMA}

Bulgular bölümünde ulaşılan veriler SPSS ve AMOS paket programları aracılığıyla değerlendirilmiştir.

\section{Araştırma Verilerinin Güvenilirliği ve Pilot Çalışma}

\section{Kavramsal yapının (çerçeve) oluşturulması;}

Madde havuzunun oluşturulması için ilgili literatür taranmış ve ölçülecek olgunun kavramsal çerçevesi (yapısı) kapsamlı bir biçimde oluşturulmuştur.

\section{Madde havuzunun oluşturulması;}

Literatürde bulunan daha önce geliştirilmiş ölçekler incelenmiş, cevaplayıcı kitlesine açık uçlu sorular sorulmuş ve ilgili uzmanların görüşleri alınarak madde havuzu oluşturulmuştur. E-nabız uygulamasının kullanılmasında etkili olan faktörleri geliştirmek için madde havuzunda, beşli Likert ölçeğine göre 23 madde oluşturulmuştur.

\section{Havuzdaki maddelerin uzman görüşüne sunulmasl;}

İncelenecek olguyla ilgili ciddi bilgi alt yapısına sahip 10 uzman, havuzdaki her bir maddeyi incelemiş ve kavramsal çerçeve göz önüne alınarak maddelerin tamamının taslak ölçekte kalmasına karar verilmiştir.

\section{Pilot çalışmanın yapılması;}

Taslak ölçekle 20 kişi üzerinde pilot çalışma yapılarak maddelerdeki ifade hataları, cevaplayanlar tarafindan yanlış anlaşılma durumları, yazım hataları, imla hataları vb. hatalar düzeltilmiştir.

\section{Test yeniden test güvenilirliğinin yapılması;}

Test yeniden test güvenilirliği için taslak ölçek 30 kişiye 2 haftalık zaman aralığıyla, iki defa uygulanmıș ve ölçekten alınan toplam puanlar aşağıda verilmiştir. Birinci ve ikinci uygulama arasindaki Pearson korelasyon katsayısının düzeyi (derecesi) 0,868 'dir $(\% 86,8)$. Yani, birinci ve ikinci uygulama arasında çok kuvvetli (çok yüksek) pozitif korelasyon vardır. Bulunan korelasyon katsayıs1, aynı zamanda kararlılık katsayısıdır. Yani, kararlılık katsayısı $\rho=0,868$ 'dir. Kararlılık katsayısının çok yüksek olması, farklı zamanlarda yapılan ölçümlerin çok benzer olduğunu göstermektedir. $\mathrm{Bu}$ durum da ölçeğin, oldukça kararlı bir ölçek olduğunu göstermektedir. Kararlılık aynı zamanda bir güvenilirlik göstergesi olduğundan, ölçek yüksek derecede güvenilirdir.

\section{Hedef kitleye taslak ölçeğin uygulanması;}

1215 kişiye internet üzerinden anket tekniği (online anket) uygulanmıştır.

İç tutarlılık güvenilirliği için madde analizinin yapılması;

Güvenilirlik analizi için hedef kitleden elde edilen verilere, "Madde-toplam korelasyonuna dayalı madde analizi" yapılmış ve bütün maddelerin uyum sağladığ 1 görülerek 23 madde ile analize devam edilmiştir. 23 madde için yapılan güvenilirlik katsayısı Alfa $=0,968$ olarak bulunmuştur.

\section{Demografik Bulgular}

Araştırmaya katılan bireylerin \%55'ini erkek, \%45'ini kadın yöneticiler oluştururken; \%73'ünü orta yaş gurubu (3655 aras1) yöneticiler oluşturmakta, \%48'ini üniversite mezunu yöneticiler, \%73'ünü orta kademe, $\% 27$ 'sini ise üst kademe yöneticiler oluşturmaktadır. 


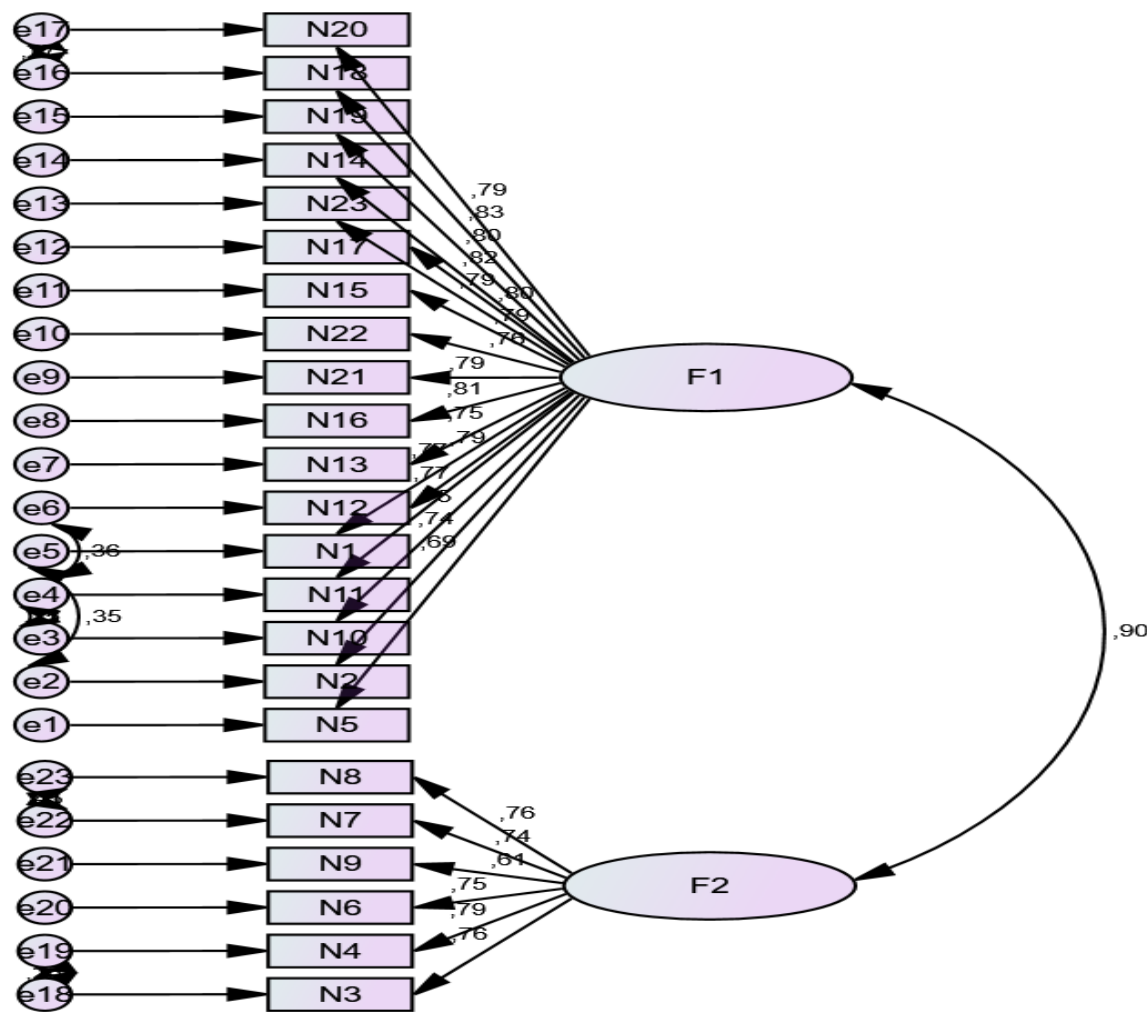

[(X²/df: 2,673; GFI: 0,899; NFI: 0,934; CFI: 0,943; RMR: 0,045; TLI: 0,90; IFI: 0,943; AGFI: 0,875; RMRSEA: 0,069)]

Şekil 1. E-Nabız Uygulamasının Kullanılmasında Etkili Olan Faktörler Araştırma Modeli ve Uyum İyiliği Sonuçları

Yukarıda verilen, RMR, GFI, AGFI, IFI, TLI, CFI, NFI, RMSEA değerleri model uyumunun (model fit) sağlandığını göstermektedir. Ayrıca ölçüm modelinin geçerlilik ve güvenilirliğini belirlemek amacıyla hesaplanan faktörlerin açıklanan varyansları, $\mathrm{t}$ değerleri, standart hata değerleri ve $\mathrm{p}$ değerleri Tablo 2'de verilmiştir.

Tablo 2. Ölçüm Modeline İlişkin DFA Sonuçları

\begin{tabular}{cccccc}
\hline $\begin{array}{c}\text { Örtük } \\
\text { Değişkenler }\end{array}$ & $\begin{array}{c}\text { Standartlaştırılmış } \\
\text { Regresyon Katsayıları }\end{array}$ & Estimate & $\begin{array}{c}\text { Standart } \\
\text { Hata }\end{array}$ & t değeri & p \\
\hline N5 &, 688 & 1,000 & & & \\
\hline N2 &, 743 &, 994 &, 040 & 24,590 & $* * *$ \\
\hline N10 &, 749 & 1,076 &, 043 & 24,792 & $* * *$ \\
\hline N11 &, 772 & 1,112 &, 044 & 25,484 & $* * *$ \\
\hline N1 &, 773 & 1,094 &, 043 & 25,536 & $* * *$ \\
\hline N12 &, 793 & 1,175 &, 045 & 26,150 & $* * *$ \\
\hline N13 &, 752 & 1,097 &, 044 & 24,877 & $* * *$ \\
\hline N16 &, 812 & 1,124 &, 042 & 26,717 & $* * *$ \\
\hline N21 &, 787 & 1,104 &, 042 & 25,967 & $* * *$ \\
\hline N22 &, 765 & 1,087 &, 043 & 25,284 & $* * *$ \\
\hline N15 &, 795 & 1,124 &, 043 & 26,205 & $* * *$ \\
\hline N17 &, 803 & 1,144 &, 043 & 26,469 & $* * *$ \\
\hline N23 &, 786 & 1,098 &, 042 & 25,928 & $* * *$ \\
\hline N14 &, 820 & 1,162 &, 043 & 26,980 & $* * *$ \\
\hline N19 &, 800 & 1,155 &, 044 & 26,380 & $* * *$ \\
\hline
\end{tabular}




\begin{tabular}{cccccc}
\hline $\begin{array}{c}\text { Örtük } \\
\text { Değişkenler }\end{array}$ & $\begin{array}{c}\text { Standartlaştırılmış } \\
\text { Regresyon Katsayıları }\end{array}$ & Estimate & $\begin{array}{c}\text { Standart } \\
\text { Hata }\end{array}$ & t değeri & p \\
\hline N18 &, 830 & 1,166 &, 043 & 27,271 & $* * *$ \\
\hline N20 &, 789 & 1,131 &, 044 & 26,002 & $* * *$ \\
\hline N3 &, 756 & 1,000 & & & \\
\hline N4 &, 793 & 1,061 &, 033 & 32,523 & $* * *$ \\
\hline N6 &, 750 & 1,025 &, 039 & 26,099 & $* * *$ \\
\hline N9 &, 612 &, 893 &, 043 & 20,958 & $* * *$ \\
\hline N7 &, 738 & 1,073 &, 042 & 25,573 & $* * *$ \\
\hline N8 &, 756 & 1,073 &, 041 & 26,284 & $* * *$ \\
\hline
\end{tabular}

$* * * \mathrm{p}<0.01$

Tablodaki her ikili ilişki için "p" değerlerinin 0,001 'den küçük çıkması, maddelerin faktörlere doğru yüklendiğini göstermektedir. Ayrıca standardize edilmiş regresyon katsayılarının 0,612 ve daha büyük olması gizli değişkenleri tahmin etme gücünün, yani her bir maddenin faktör yüklenimlerinin yüksek olduğunu göstermektedir. Aşağıdaki Tablo 3'de literatürde genel kabul gören iyilik uyum indeksi değerleri analiz sonrası elde edilen değerler gösterilmiştir.

Tablo 3. Ölçüm Modeli Uyum İyiliği İndeksleri

\begin{tabular}{cccc}
\hline $\begin{array}{c}\text { Genel Model } \\
\text { Uyumu }\end{array}$ & İyi Uyum & $\begin{array}{c}\text { Kabul Edilebilir } \\
\text { Uyum }\end{array}$ & $\begin{array}{c}\text { Elde Edilen } \\
\text { Uyum Değerleri }\end{array}$ \\
\hline $\mathbf{x}^{2} /$ sd & $\leq 3$ & $\leq 5$ & $\mathbf{2 , 6 7 3}$ \\
\hline NFI & $\geq 0,95$ & $\geq 0,90$ & $\mathbf{0 , 9 3 4}$ \\
\hline CFI & $\geq 0,97$ & $\geq 0,95$ & $\mathbf{0 , 9 4 3}$ \\
\hline IFI & $\geq 0,95$ & $0,94-0,90$ & $\mathbf{0 , 9 4 3}$ \\
\hline AGFI & $>0,95$ & $\geq 0,85$ & $\mathbf{0 , 8 7 5}$ \\
\hline GFI & $\geq 0,90$ & $0,89-0,85$ & $\mathbf{0 , 8 9 9}$ \\
\hline RMR & $<0,05$ & $<0,08$ & $\mathbf{0 , 0 4 5}$ \\
\hline
\end{tabular}

Tablo 3'de görüldüğü üzere elde edilen sonuçlar, önerilen araştırma modelinin uyum indekslerinin kabul edilebilir uyum düzeyinde olduğunu göstermektedir. Açıklayıcı ve doğrulayıcı faktör analizleri ile elde edilen bulgular, modelin yap1 geçerliliğinin sağlandığını göstermektedir. Açıklayıcı faktör analizi ile ortaya konulan yapı geçerliliği, doğrulayıcı faktör analizi ile de teyit edilmiştir. Güvenilirlik katsayısı $\mathrm{Alfa}=0,968$ olarak bulunmuştur. $\mathrm{Bu}$ değer $0,80 \leq \alpha<1,00$ arasında olduğundan, ölçek yüksek derecede güvenilirdir. Dolayısıyla "enabız ölçeği”" için geçerlilik ve güvenilirlik sağlandığından "e-nabız ölçeğì" e-nabız uygulamalarının kullanımına yönelik tutumları ve beklentileri ölçmek için rehber ölçek olarak kullanılabilir.

\section{Farklılık Analizleri Bulguları}

Araştırmanın bu bölümünde e-nabız uygulamalarının kullanımına yönelik tutumu ifade eden "algılanan fayda" ve "kullanım kolaylığı" değişkenleri ile hastane yöneticilerinin demografik özellikleri arasında farklilık testleri ( $\mathrm{t}$-testi ve ANOVA) yapılmıştır.

Tablo 4: Yöneticilerin Cinsiyetlerine Göre T-Testi Sonuçları

\begin{tabular}{|c|c|c|c|c|c|c|}
\hline Faktörler & $\begin{array}{c}\text { Cinsiyet } \\
\text { Grubu }\end{array}$ & $\mathbf{N}$ & Ortalama & $\begin{array}{c}\text { Standart } \\
\text { Sapma }\end{array}$ & $\mathbf{t}$ & $\mathbf{p}$ \\
\hline \multirow{2}{*}{ Algilanan Fayda } & Erkek & 664 & 3,6579 &, 85989 & \multirow{2}{*}{$-2,780$} & \multirow{2}{*}{, $006 *$} \\
\hline & Kadın & 551 & 3,7935 & ,83571 & & \\
\hline \multirow{2}{*}{ Kullanım Kolaylığı } & Erkek & 664 & 3,5781 & ,88636 & \multirow{2}{*}{$-1,022$} & \multirow{2}{*}{,307 } \\
\hline & Kadın & 551 & 3,6298 &, 87053 & & \\
\hline
\end{tabular}

*Gruplar arası farklılık 0,005 düzeyinde anlamlıdır. 
Tablo incelendiğinde yöneticilerin algılanan faydaya yönelik algıları cinsiyetlerine göre anlamlı bir farklılık göstermektedir. Algılanan fayda konusunda kadın yöneticilerin erkek yöneticilere göre daha olumlu bir tutum içerisinde oldukları görülmüştür.

Tablo 5. Yöneticilerin Eğitim Durumu ve Yaş Durumu ANOVA Sonuçları

\begin{tabular}{|c|c|c|c|c|c|c|c|}
\hline \multicolumn{8}{|c|}{ Eğitim Durumu } \\
\hline Faktörler & $\begin{array}{l}\text { Varyansın } \\
\text { Kaynağı }\end{array}$ & $\begin{array}{l}\text { Kareler } \\
\text { Toplamı }\end{array}$ & Sd & $\begin{array}{c}\text { Kareler } \\
\text { Ort. }\end{array}$ & $\mathbf{F}$ & $\mathbf{p}$ & Anlamlı Fark \\
\hline \multirow{3}{*}{ Algilanan Fayda } & Gruplararası & 3,442 & 4 &, 860 & 1,188 &, 314 & \multirow{3}{*}{$\begin{array}{l}\text { Lisansüstü- } \\
\text { Üniversite }\end{array}$} \\
\hline & Grupiçi & 876,465 & 1210 & ,724 & & & \\
\hline & Toplam & 879,906 & 1214 & & & & \\
\hline & & & & & & & \\
\hline \multirow{3}{*}{ Kullanım Kolaylığ } & Gruplararası & 7,444 & 4 & 1,861 & 2,419 &, $047 *$ & \multirow{3}{*}{$\begin{array}{l}\text { Lisansüstü- } \\
\text { Lise }\end{array}$} \\
\hline & Grupiçi & 931,037 & 1210 & ,769 & & & \\
\hline & Toplam & 938,481 & 1214 & & & & \\
\hline \multicolumn{8}{|c|}{ Yaş Durumu } \\
\hline \multirow{4}{*}{ Algilanan Fayda } & $\begin{array}{l}\text { Varyansın } \\
\text { Kaynağı }\end{array}$ & $\begin{array}{l}\text { Kareler } \\
\text { Toplamı } \\
\end{array}$ & Sd & $\begin{array}{c}\text { Kareler } \\
\text { Ort. }\end{array}$ & $\mathbf{F}$ & $\mathbf{p}$ & Anlamlı Fark \\
\hline & Gruplararası & 21,315 & 4 & 5,329 & 7,510 &, $000 *$ & \multirow{3}{*}{$\begin{array}{c}\text { 36-45 arası } \\
\text { ile } 56 \text { ve } \\
\text { üzeri }\end{array}$} \\
\hline & Grupiçi & 858,591 & 1210 & ,710 & & & \\
\hline & Toplam & 879,906 & 1214 & & & & \\
\hline \multirow{3}{*}{ Kullanım Kolaylığı } & Gruplararas1 & 12,025 & 4 & 3,006 & 3,926 &, $004 *$ & \multirow{3}{*}{$\begin{array}{l}36-45 \text { arası ile } \\
56 \text { ve üzeri }\end{array}$} \\
\hline & Grupiçi & 926,455 & 1210 & ,766 & & & \\
\hline & Toplam & 938,481 & 1214 & & & & \\
\hline
\end{tabular}

Tablo 5 incelendiğinde sadece kullanım kolaylığı faktörünü algılamaları bakımından yöneticilerin mezun oldukları okul grupları arasında anlamlı bir fark olduğu (Post Hoc testi sonucunda lisansüstü eğitim düzeyine sahip bireyler, lise eğitim düzeyine sahip olan bireylere göre e-nabız uygulamalarını daha kolay kullanabildikleri için tercih ettikleri) görülmektedir. Dolayısıyla kullanım kolaylığg faktöründe lisansüstü mezunların, lise mezunlarına göre daha olumlu bir tutum sergiledikleri görülmüştür.
Benzer şekilde hem algilanan fayda hem de kullanım kolaylığı faktörlerini algılamaları bakımından yöneticilerin yaş grupları arasında anlamlı bir fark olduğu (Post Hoc testi sonucunda 36-45 yaş arası bireyler, 56 ve üzeri yaş grubu bireylere göre e-nabız uygulamalarını daha faydalı algıladıkları ve daha kolay kullanabildikleri için tercih ettikleri) görülmektedir. Algilanan fayda ve kullanım kolaylığg faktörlerinde orta yaş grubu yöneticilerin, ileri yaş grubu yöneticilere göre daha olumlu bir tutum sergiledikleri görülmüştür.

\section{SONUÇ VE ÖNERILER}

E-nabız uygulamalarının kullanımına yönelik tutumları ölçmeye yarayan bir ölçeğin geliştirilmesi ve nüfusun her gün arttığı gelişmekte olan ülkelerde sağlık hizmetleri sisteminin yararlarına ve zorluklarına katkıda bulunması amacıyla yapılan bu çalışma, Türkiye'de faaliyet gösteren JCI (Joint Commission International) akreditasyon belgeli 48 adet özel hastanenin konuyla ilgili orta ve/veya üst kademe yöneticileri üzerinde 
yürütülmüştür. $\mathrm{Bu}$ araştırmadan elde edilen sonuçlar aşağıda verilmiştir:

Açıklayıcı faktör analizi sonuçlarına göre; e-nabız uygulamasının kullanılmasında etkili olan faktörler 2 farklı boyut altında toplanmıştır. Bu boyutlar; "algılanan fayda" ve "kullanım kolaylığı" şeklinde literatüre dayandırılarak isimlendirilmiştir.

$\mathrm{Bu}$ çalışmanın sonuçlarıyla benzer bir şekilde, Yeşiltaş ${ }^{15}$ tarafından yapılan bir çalışmada; e-abız uygulamasının faydalı, kullanımı kolay ve gerekli bir uygulama olduğu ve sağlik hizmetlerinden faydalanmayı kolaylaştırdığı sonucuna ulaşılmıştır. Aynı şekilde Soysal ve Yalçın ${ }^{16}$ tarafından yapılan araştırmada e-nabız sistemini kullanan kişilerin; uygulamanın, hastalık, alerji vb. gibi durumların kayıt altına alınmasını sağlaması, mobil cihazlar için ilaç hatırlatma uyarısında bulunması, kolay ulaşılabilir olması ve verileri tek bir yerde toplamas1, randevu alma veya iptal etme işlemi yapılabilmesi, alınan sağlık hizmetlerini değerlendirebilme olanağı sağlaması ve kolay kullanılabilir olması gibi nedenlerden dolayı faydalı buldukları tespit edilmiştir. Kıraç ve Yılmaz ${ }^{17}$ tarafından yapılan çalışmada da, katılımcıların çoğu enabız sistemini faydalı bulduklarını ve genel olarak memnun olduklarını belirtmişlerdir.

Doğrulayıcı faktör analizi yapılarak; enabız uygulamasının kullanılmasında etkili olan faktörler arasındaki ilişkilerin kabul edilebilir uyum indeksine sahip olduğu görülmüştür. Tüm değişkenler için yapılan güvenilirlik analizinde, ölçeğin yüksek güvenilirlik seviyesine sahip olduğu görülmüştür. Bunun yanı sıra önerilen araştırma modelinin uyum indekslerinin kabul edilebilir uyum düzeyinde olduğunu görülmüştür. Aynı zamanda açıklayıcı ve doğrulayıcı faktör analizleri ile elde edilen bulgular, modelin yap1 geçerliliğinin sağlandığını göstermiștir. Açıklayıcı faktör analizi ile ortaya konulan yapı geçerliliği, doğrulayıc1 faktör analizi ile de teyit edilmiştir. Güvenilirlik katsayısı Alfa $=0,968$ olarak bulunmuştur. $\mathrm{Bu}$ değer $0,80 \leq \alpha<1,00$ arasında olduğundan, ölçek yüksek derecede güvenilirdir. Dolayısıyla "e-nabız ölçeği” için geçerlilik ve güvenilirlik sağlandığından "e-nabız ölçeği” e-nabız uygulamalarının kullanımına yönelik tutumları ve beklentileri ölçmek için rehber ölçek olarak kullanılabilir.

Yapılan bu araştırmada yöneticilerin enabız uygulamasına yönelik tutumları ile onların eğitim düzeyleri arasında anlamlı ilişki bulunmuştur. Eğitim düzeyi yüksek sağlık yöneticilerin güncel gelişmeleri daha yakından takip ettikleri ve çalıştıkları sektör ve bulundukları ortam nedeniyle bilgiyi aramaya yönelik davranışlar sergiledikleri, bu durumun nedeni olarak düşünülmektedir. Benzer şekilde yöneticilerin e-nabız uygulamasına yönelik tutumlarının yaş grupları ile doğru orantılı olduğu görülmektedir. Orta yaş grubu yöneticilerin e-nabız uygulamalarını daha aktif kullandıkları ve e-nabız sistemine kayıt olma durumlarının daha yüksek olduğu, bu durumun nedeni olarak düşünülmektedir.

Sonuç olarak yapılan bu çalışma, sağlık yöneticilerinin e-sağlık, mobil sağlık ve enabız konusunda neleri, ne kadar ve ne derece doğru bildiklerinin ve kullandıklarının tespit edilmesinde ve e-sağlık hizmetlerinin evriminin incelenmesinde daha net bir vizyonun oluşturulmasında ve düzenli ve sürdürülebilir e-sağlık hizmetlerinin kullanılmasında ve e-sağlık uygulamalarının desteklenmesinde ölçülü bir katkı sağlamaktadır.

$\mathrm{Bu}$ bağlamda Sağlık Bakanlığı'nın esağlık, m-sağlık ve e-nabız uygulamalarının kullanılması hususunda halkı bilgilendirmek ve farkındalık oluşturmak amacı ile kamu spotları ve broşürler hazırlanması ve hizmet içi eğitimler düzenlemesinin daha faydalı olacağı düşünülmektedir. Aynı zamanda esağlık uygulamalarının etkin bir şekilde kullanılması, bireylerin sağlık hizmetlerine ulaşımını kolaylaştırmasının yanı sıra sağlık hizmetlerine olan memnuniyet düzeylerini ve sağlı hizmet kalitesi algılarını da artıracaktır. Dolayısıyla hızlı, etkili, verimli ve proaktif bir uygulama olan e-nabiz uygulamasının yaygınlığının ve kullanım sıklığının artırılması hedeflenmelidir. 


\section{KAYNAKLAR}

1. Mukherjee, A. and Mcginnis, J. (2007). "E-Healthcare: An Analysis of Key Themes in Research" International Journal of Pharmaceutical and Healthcare Marketing, 1 (4), 349-363.

2. Rohm, B.W.T. and Rohm, C.E.T.Jr. (2002). "A Vision of the EHealthcare Era". International Journal of Healthcare Technology and Management, 4 (1-2), 87-92.

3. Abolade, T.O. and Durosinmi, A.E. (2018). "The Benefits and Challenges of E-Health Applications in Developing Nations: A Review". Proceedings of the 14th ISTEAMS International Multidisciplinary Conference, AlHikmah University, Ilorin, Nigeria, 14, 37-44

4. Griskewicz, M. (2002). "HIMSS SIG Develops Proposed eHealth Definition". HIMSS News, 13 (7), 5

5. Şat, S.Ö., Sözbir, Ş.Y. (2018). "Use of mobile applications and blogs by pregnant women in Turkey and the impact on adaptation to pregnancy". Midwifery, 62, 273-277.

6. Krebs, P. and Duncan, D.T. (2015). "Health app use among US mobile phone owners: a national survey". JMIR mHealth and uHealth, 3(4), 7.

7. TÜİK (2017). Use of Information and Communication Technology (ICT). Ankara: Türkiye İstatistik Kurumu.

8. Genitsaridi, I, Kondylakis, H. and Koumakis, L.M. (2015). "Evaluation of personal health record systems through the lenses of EC research projects". Computers in Biology and Medicine, 59, 175-185.

9. Rowan, M. and Dehlinger, J. (2014). “A Privacy Policy Comparison of Health and Fitness Related Mobile Applications”. Procedia Computer Science, 37, 348-355.
10. Catan, G, Espanha, R, Veloso Mendes, R, Toren, O. and Chinitz, D. (2015). "The Impact of eHealth and mHealth on doctor behavior and patient involvement: an Israeli and Portuguese comparative approach," Stud Health Technol Inform, 210, 813-817.

11. Tseng, C.H. and Wei, L.F. (2020). "The efficiency of mobile media richness across different stages of online consumer behavior." International Journal of Information Management, $50,353-364$.

12. Alalwan, A.A. (2020). "Mobile food ordering apps: An empirical study of the factors affecting customer e-satisfaction and continued intention to reuse." International Journal of Information Management, 50, 28-44.

13. SATURK (2018). Türkiye'de Sağlık Hizmetine Kolay Erișim. Ankara: Sağlık Turizmi Daire Başkanlığı.

14. T.C. Sağlık Bakanlığı (2018). E-Nabız v.2.0 Kullanım kılavuzu. Ankara: T.C. Sağlık Bakanlığı.

15. Yeşiltaş, A. (2018). "E-Nabız Uygulamasının Kullanımını Etkileyen Faktörler." Sağlık Akademisyenleri Dergisi, 5(4), 290-295.

16. Soysal, A. ve Yalçın, T. (2019). "Bazı Demografik Değişkenlere Göre E-Nabız Sisteminin Kullanımı: Öğrenciler Üzerinde Bir Araştırma.” Sağlık Akademisyenleri Dergisi, 6(3), 180-188.

17. Kıraç, R. ve Yılmaz, G. (2019). "Yetişkinlerde E-Nabız Sistemi Farkındalığının Belirlenmesine Yönelik Bir Araştırma.” 3. Uluslararası 13. Ulusal Sağlık ve Hastane İdaresi Kongresi, 1013 Ekim 2019, Sakarya. 